\title{
Desvios na Estrada
}

\author{
CLAUDIA DA SILVA PEREIRA*
}

\section{GOLDENBERG, Mirian. \\ De Perto Ninguém é Normal \\ Rio de Janeiro: Record, 2005.}

De perto ninguém é normal marca os dez anos de estrada de Mirian Goldenberg como professora da Universidade Federal do Rio de Janeiro e reúne o supra-sumo das idéias da antropóloga, que vem-se dedicando a um campo de pesquisa que ela mesma denomina como "gênero e desvio".

Seus estudos falam diretamente à nossa subjetividade, às nossas diversas identidades, àquilo que está presente no cotidiano, entre quatro paredes e nas ruas. Somados a conclusões recentes da autora, seus trabalhos estão presentes nesse livro, por vezes provocativo e, na maioria do tempo, esclarecedor sobre as diversas faces - convencionais e desviantes - da sociedade em que vivemos. E é logo de início que o leitor se vê diante de uma constatação nem sempre confortável: desviantes somos todos, eu, você, ela e ele, mas poucos de nós temos coragem para levar a cabo impulsos que podem desestabilizar-nos na vida social. Normal, enfim, ninguém é de verdade.

A sós, em nossas fantasias ou nus diante do espelho, tudo pode acontecer. A própria autora olha, com coragem, para seu reflexo do outro lado, que revela, para além da antropóloga, uma mulher preocupada com sua aparência. Assim, no capítulo que abre o livro, "A conversão do pesquisador", Goldenberg escreve sobre a difícil arte de pesquisar, que começa pelo contágio que, na maioria das vezes, acontece entre antropólogo e objeto de estudo. No seu caso, que publicou livros como A Outra (1991) e Toda mulher é meio Leila Diniz (1995), a experiência de escolher temas considerados pouco convencionais pela Academia rendeu (e continua rendendo) momentos de conflito e autoconhecimento.

Essas escolhas, mesmo à sua revelia, aderiram-lhe um rótulo de desviante. É o objeto contagiando o antropólogo aos olhos do Outro. Ao mesmo 
tempo, acontece de o pesquisador tornar-se, ao longo do trabalho de campo, um nativo como aqueles que servem à sua observação. Aqui, é o objeto contagiando o antropólogo aos olhos da sedução. Sedução que levou Goldenberg, através de seus estudos sobre corporalidade, a tornar-se uma consumidora entusiasmada de cosméticos contra o envelhecimento, os mesmos que, convictamente acredita, servem a um estabelecido padrão de beleza feminino que aprisiona e domina. Ossos do ofício.

A partir de uma pesquisa que vem realizando desde 1998, entrevistas com 1.279 homens e mulheres de camadas médias do Rio de Janeiro fazem a autora atribuir ao corpo o papel de sujeito social no mercado afetivo-sexual, o que o torna, conseqüentemente, alvo de um culto cada vez maior de mulheres de todos os segmentos da sociedade brasileira. O que chamou sua atenção é a recorrência, no discurso de seus entrevistados, de uma categoria um tanto quanto subjetiva - "o corpo", fato que traz à tona uma série de reflexões que nos ajudam a compreender as representações de gênero na contemporaneidade.

No segundo capítulo do livro, "O corpo cativo: sedução e escravidão feminina", Goldenberg demonstra que tanto homens quanto mulheres valorizam o corpo como um agente que favorece a atração física e sexual, juntamente com a inteligência, o olhar e a beleza. Porém, para as mulheres, a busca por um padrão de beleza instaurado pelo sucesso das magras e esguias top models está se tornando uma obsessão, impedindo-as de se realizarem afetiva e sexualmente. Os homens, ao contrário, declaram preferir um padrão de beleza nas mulheres que se aproxima mais das "gostosas". O resultado é, segundo as conclusões da pesquisa, "um divórcio" entre os discursos masculino e feminino. Para eles, as mulheres estão fake demais. Apesar de a oferta de mulheres disponíveis ser grande no mercado afetivo-sexual, a exagerada preocupação com o corpo as tem feito se afastar daquilo que, para os homens, faz a diferença: o charme, a inteligência, a boa conversa, por exemplo. Para elas, os poucos exemplares masculinos disponíveis estão exigentes demais, daí o alto grau de insatisfação com seus corpos naturais, feitos de gordurinhas, estrias e celulites que vêm com o tempo.

Se, por um lado, a distância é grande entre as percepções sobre o corpo entre homens e mulheres, no quesito sexo ela parece diminuir. Entre os mais jovens entrevistados pela antropóloga, a idade da iniciação sexual concentrou-se em torno da faixa de 16 anos, tanto para eles quanto para elas. Mas a aproximação pára por aí. A virgindade ainda é mais comum entre as jovens, assim como um menor número de parceiros, comparativamente aos 
homens. Em "A dominação masculina na juventude", Goldenberg aponta para a vigência de valores tradicionais em meio a uma vontade moderna da sociedade. Assim, o que se encontra é uma identidade masculina construída sobre um discurso que valoriza a variedade de parceiras e a maior freqüência das relações sexuais, enquanto que, entre as mulheres, perde-se a virgindade mais cedo, mas espera-se delas um número restrito de parceiros. É, segundo a autora, uma "dupla moral" que as coloca mais livres para decidir sobre a sua primeira experiência e que, ao mesmo tempo, as mantém presas à afetividade que vincula sexo e amor. Um comportamento sexual diferente desse padrão é considerado desviante, segundo as conclusões da antropóloga.

Os jovens entrevistados que participaram da pesquisa de Goldenberg também foram convidados a eleger características que são objeto de inveja e de desejo entre seus pares e no sexo oposto. Os resultados confirmam um padrão de identidade tradicional entre os gêneros que coloca em evidência a preocupação com o corpo, mas com pontos de vista diferentes que denotam uma vantagem masculina. Entre os homens, por exemplo, tamanho ainda é documento e o grau de exigência com sua própria aparência física é menor se comparado com o das jovens. Ainda entre eles, há mais coisas a serem desejadas do que invejadas nas mulheres. Para as entrevistadas, pelo contrário, ser loura e magra faz a diferença. E suas invejas com relação ao sexo oposto recaem sobre aquilo que faz parte de sua natureza: eles "não menstruam", "não sentem cólicas", "não têm seios" e "fazem xixi em pé" são algumas das "vantagens" masculinas, segundo elas. A autora conclui que, apesar dos avanços conquistados pelas mulheres na sociedade, os valores tradicionais reafirmam uma dominação masculina que acaba por aprisionar, também, os homens num ideal de virilidade relacionado a um determinado modelo de corpo e virilidade.

Em outro capítulo, "Compromissos não-obrigatórios nas camadas médias urbanas", descobre-se que a fronteira entre tradição e modernidade é mais uma vez derrubada, agora dentro de casa. Homens e mulheres, cada um na sua medida, objetivam relacionamentos que respeitem a individualidade e a privacidade de cada um, mas sem abrir mão dos sentimentos que a autora chama de "simbióticos": a cumplicidade, o companheirismo, a dedicação, a complementaridade entre os cônjuges, os projetos compartilhados. As novas conjugalidades, tomadas por alguns entrevistados como desviantes devido ao não-compromisso formal, estão presentes na contemporaneidade, momento em que não cabem mais os valores tradicionais do casamento e da família. Por outro lado, esses mesmos arranjos conjugais são interpenetrados pelo ideal do 
amor romântico, que acaba por entrar em conflito com o desejo comum de liberdade, possibilitado, principalmente, pela independência financeira feminina.

No embate entre essas duas forças, a fidelidade é um desafio: como ser, ao mesmo tempo, cúmplice e dono de sua própria privacidade? Como ser companheiro sem abrir mão da liberdade reivindicada? Para os homens, ser infiel é algo inerente à sua condição, já que eles traem para, de uma certa forma, fazer valer sua virilidade. Para as mulheres, que hoje também traem (embora em menor grau), a infidelidade é uma resposta às faltas do cônjuge. Neste sentido, é consenso que a culpa da traição é sempre deles.

O lugar dos gêneros nas relações a dois e a crise do casamento e da família brasileira também são temas centrais em "Laços de Família: novas conjugalidades na novela das oito", onde Goldenberg analisa a trama televisiva, que bateu recordes de audiência em 2000, à luz da Antropologia. O olhar observador da autora percebeu que, por trás da grande polêmica causada pela novela, entre processos judiciais, censuras, críticas de religiosos e fofocas, o que se retratou foram os novos arranjos conjugais presentes na sociedade brasileira, reforçando os laços de sangue - através dos filhos - como regeneradores da ordem. Mais ainda, os destinos dos personagens, a princípio condenados por suas vidas consideradas desviantes - uma garota de programa, uma adolescente virgem, mães solteiras, entre outros - foram traçados, no final da trama, por linhas bastante conservadoras: a garota de programa reabilitouse, a adolescente casou-se virgem com o homem que amava, as mães solteiras também se casaram, os vilões morreram... A partir das reflexões da autora sobre a novela "Laços de Família", chega-se a um modelo tradicional de papéis sociais em que homens apaixonados e viris, e mulheres dedicadas a seus filhos e maridos encontram a felicidade nos laços das novas conjugalidades que estão longe de ser ficção na sociedade brasileira.

Os dois últimos capítulos de De perto ninguém é normal percorrem trajetórias políticas para, comparativamente, demonstrar, também na militância, de que forma são construídas as identidades de figuras proeminentes consideradas desviantes. Em "Mulheres e Militantes", Maria Prestes, Clara Charf e a anônima "Maricota da Silva" representam uma geração de mulheres "invisíveis" que construíram seus nomes na história da esquerda no Brasil através dos homens que as precederam - maridos, pais e irmãos. Olga Benário e Iara Iavelberg, que também estariam condenadas à obscuridade, ganharam reconhecimento por seus feitos e hoje ocupam lugar de destaque, mas sempre 
associadas a seus companheiros, respectivamente, Luis Carlos Prestes e Carlos Lamarca. Iná Meireles, primeira mulher a ter alcançado o cargo de presidente da CUT e que tem seu lugar em anos mais recentes e feministas dessa história, surge no estudo de Goldenberg com uma trajetória que demonstra a conquista - dura e árdua - das mulheres que já conseguem sair da sombra de figuras masculinas para, respeitando sua individualidade e independência, mostrar a que vieram neste "mundo dos homens".

Partindo de reportagens, biografias e longas entrevistas, a autora revela que a geração feminina dos anos 30, no cenário clandestino da militância, ocupava funções consideradas menores, garantindo a segurança e o dia-a-dia de seus maridos. Aqui, os papéis tradicionais femininos, como limpar, cozinhar, proteger e secretariar, ofuscavam seus ideais, que não eram calados por falta de competência, mas por falta de voz dentro de um ambiente machista. No capítulo que fecha o livro, "Bandido ou Herói?", o guerrilheiro baiano Carlos Marighella, morto em 1969 pela polícia, tem sua trajetória analisada pela antropóloga através de matérias jornalísticas da época, que ajudaram a construir sua imagem paradoxal de "bandido" e de "herói". Transportada para os dias atuais, a trajetória desse homem, a um só tempo acusado de "terrorista" e valorizado como "guerrilheiro", assemelha-se, segundo a autora, ao de traficantes e governantes. O discurso presente na mídia, através de adjetivos como "bandido", "terrorista", "assassino", "marginal", "frio", "cruel", "déspota", entre outros, constrói a imagem mítica de personagens que os aproximam de símbolos de poder, riqueza, inteligência e sucesso. Por vezes, a singularidade de suas vidas transforma-se numa trajetória muito mais bandida ou heróica do que efetivamente é.

Os desvios na estrada da antropóloga, pesquisadora e professora Mirian Goldenberg levam-nos a diversas direções. De perto ninguém é normal é a esquina em que esses caminhos, aparentemente distantes, encontram-se; em que tradição e modernidade convivem; em que subjetividade e objetividade dialogam. O livro é, enfim, o quebra-molas da viagem que nos faz frear e acordar para temas que, por serem tão presentes em nossas vidas, muitas vezes se perdem na paisagem.

\section{NOTA}

* Doutoranda do Programa de Pós-graduação em Sociologia e Antropologia, do Instituto de Filosofia e Ciências Humanas da Universidade Federal do Rio de Janeiro. Endereço eletrônico: caupereira@uol.com.br. 